\title{
Using immediate-early genes to map hippocampal subregional functions
}

\author{
Stepan Kubik, ${ }^{1,2,3}$ Teiko Miyashita, ${ }^{1}$ and John F. Guzowski ${ }^{1,3}$ \\ ${ }^{1}$ Department of Neurobiology and Behavior Center for the Neurobiology of Learning and Memory, University of California, Irvine, \\ Irvine, California 92697-3800, USA; ${ }^{2}$ Department of Neurophysiology of Memory, Institute of Physiology, Academy of Sciences \\ of the Czech Republic, Prague, Czech Republic
}

\begin{abstract}
Different functions have been suggested for the hippocampus and its subdivisions along both transversal and longitudinal axes. Expression of immediate-early genes (IEGs) has been used to map specific functions onto neuronal activity in different areas of the brain including the hippocampus (IEG imaging). Here we review IEG studies on hippocampal functional dissociations with a particular focus on the CA3 subregion. We first discuss the cellular functions of IEGs and the brain system interactions that govern their dynamic expression in hippocampal neurons to provide a more solid framework for interpreting the findings from IEG studies. We show the pitfalls and shortcomings of conventional IEG imaging studies and describe advanced methods using IEGs for imaging of neuronal activity or functional intervention. We review the current IEG evidence of hippocampal function, subregional-specific contribution to different stages of memory formation, systems consolidation, functional dissociation between memory and anxiety/behavioral inhibition along the septotemporal axis, and different neural network properties of hippocampal subregions. In total, IEG studies provide support for (1) the role of the hippocampus in spatial and contextual learning and memory, (2) its role in continuous encoding of ongoing experience, (3) septotemporal dissociations between memory and anxiety, and (4) a dynamic relationship between pattern separation and pattern completion in the CA3 subregion. In closing, we provide a framework for how cutting-edge IEG imaging and intervention techniques will likely contribute to better understanding of the specific functions of CA3 and other hippocampal subregions.
\end{abstract}

The hippocampus lies at the crossroads of information processing in the brain. Information arrives here from most of the cortex as well as from many subcortical regions either directly, or indirectly, via the entorhinal cortex. Activity-dependent lasting potentiation of synaptic transmission, postulated as a mechanism of memory formation in the brain (Hebb 1949), was first observed in the hippocampus (long-term potentiation or LTP; Bliss and Lomo 1973). Place cells, neurons with spatially selective activity, were discovered in the hippocampus (O'Keefe and Dostrovsky 1971) and suggested to form a neural substrate of "cognitive maps" (O'Keefe and Nadel 1978). Indeed, damage to the hippocampus disrupts navigation that requires memory for spatial relationships, but not navigation to a visible cue in a water maze (Morris et al. 1982). These findings suggested that the hippocampus plays a specific role in spatial memory. In humans, damage to the hippocampus results in severe deficits in declarative memory (Scoville and Milner 1957; for review, see also Squire et al. 2004). The hippocampus is also necessary for memory of the context in which events occur (Kim and Fanselow 1992; Anagnostaras et al. 1999; Biedenkapp and Rudy 2007; Lehman et al. 2007; Wiltgen and Silva 2007), consistent with a critical role of the hippocampus in context-rich episodic memory (Vargha-Khadem et al. 1997; Winocur et al. 2007).

The hippocampus consists of distinct subregions along its transversal axis (dentate gyrus [DG], Cornu Ammonis [CA1, CA2, and CA3]), as well as different segments along its longitudinal (septotemporal) axis. The CA3 subregion represents a "bottleneck" of hippocampal processing where information flow con-

\footnotetext{
${ }^{3}$ Corresponding authors.

E-mail stepan.k@uci.edu; fax (949) 824-8439.

E-mail john.g@uci.edu; fax (949) 824-8439.

Article is online at http://www.learnmem.org/cgi/doi/10.1101//m.698107.
}

verges from $>1,000,000$ dentate granule cells on only $\sim 220,000$ neurons before expanding again on $\sim 400,000$ CA1 neurons in a rat (Rapp and Gallagher 1996). A unique, recurrent synaptic connectivity makes the CA3 ideally suited for an autoassociative neural network. Numerous computational models suggested that the putative functions of such a network architecture-including pattern completion, memory encoding, temporary storage, and retrieval (Marr 1971; McNaughton and Morris 1987; McClelland and Goddard 1996; Rolls and Treves 1998; Nakazawa et al. 2002), rapid single-trial learning (Nakazawa et al. 2003), or automatic recording of attended experience (Morris and Frey 1997) — may well serve to encode representations of context of events and episodic memories. Evidence for each of these functions has been obtained using a variety of approaches including lesions, electrophysiological recordings, transgenic mice, and immediate-early gene (IEG) imaging. In addition, different functions have been suggested for different longitudinal segments of the hippocampus (Bannerman et al. 2004). This review describes the contribution of IEG techniques to investigations of hippocampal function and subregional dissociations, with an emphasis on CA3.

IEGs are widely believed to play a critical role in transformation of activity in neural circuits into long-term memories in the brain (Lanahan and Worley 1998; Jones et al. 2001; Guzowski 2002). The molecular mechanisms of their cellular functions and their involvement in synaptic plasticity continue to be a matter of intense research. In an independent approach, IEGs have also been used as activity reporters, making use of their rapid induction by behavioral experience (IEG imaging). We will consider the evidence provided by IEG studies in the context of studies using other approaches that shaped the current ideas in the field.

We start this review by briefly evaluating current evidence of the cellular functions of IEGs and their role in hippocampal synaptic plasticity and memory consolidation to provide back- 
ground for interpreting the IEG imaging studies. Then, we provide an overview of the regulation of IEG expression in the hippocampus by behavior and defined brain systems interactions. We describe the basic methods using IEGs for imaging and functional studies, and point out the caveats limiting interpretations of these studies. We then discuss the IEG imaging studies mapping hippocampal function and differences in hippocampal subregional involvement during memory acquisition, consolidation, and retrieval. Several studies reported subregional and temporally selective IEG activation patterns in support of the standard theory of systems consolidation-progressive hippocampal disengagement as memories become increasingly "remote" in time. We review the evidence for systems consolidation derived from IEG imaging studies. Next, we consider studies suggesting possible dissociation of hippocampal function between memory and anxiety. We also present evidence for neuronal ensemble dynamics and network properties of hippocampal subfields CA3/CA1 converging from advanced IEG imaging studies, unit recordings, genetic ablation and theoretical modeling approaches. Finally, we summarize findings from these studies on different aspects of hippocampal function and outline possible future directions of using the IEG methods to study the respective roles of hippocampal subregions.

\section{Molecular and cellular functions of IEGs and their role in synaptic plasticity and memory consolidation}

Immediate-early genes (IEGs) are rapidly expressed following patterned synaptic stimulation, such as maximum electroconvulsive shock (MECS), high-frequency stimulation inducing LTP, and also after behavioral experience (Guzowski et al. 1999, 2001; Vann et al. 2000a; Hall et al. 2001). IEGs may be categorized into two functional classes: (1) regulatory transcription factors (RTFs), which control transcription of other "downstream" genes, and (2) effector IEGs, which directly influence cellular functions (Lanahan and Worley 1998). By virtue of their ability to regulate transcription, RTFs are well situated to globally regulate cell function and possibly induce metaplastic states (Clayton 2000; Guzowski 2002). In contrast, effector IEGs have a wide range of cellular functions, including those related to (1) cellular growth (BDNF, Narp), (2) intracellular signaling (RheB, RGS-2, and Homer $1 a)$, (3) synaptic modification or other structural changes (ArC, Homer 1a, Narp, tissue plasminogen activator [TPA], BDNF), or (4) metabolism (COX-2) (see Lanahan and Worley 1998; Guzowski 2002; and references therein). Out of the variety of IEGs, only several have been used commonly to map hippocampal activity onto behavior. These are the RTFs $c$-fos, $c$-jun, and zif 268 and effector IEGs Arc and Homer 1a. We will briefly summarize data showing a role for the RTF IEGs zif268 and c-fos in synaptic plasticity and memory consolidation, before giving a detailed overview of the cell biological functions of the effector IEG Arc and its role in memory.

Late-LTP and long-term memory were impaired in various behavioral tasks including the spatial water maze in mice with genetic ablation (knockout) of the zif268 gene, even though the water maze impairments could be overcome with extended training (Jones et al. 2001). Mice with genetic ablation of the c-fos gene limited to the central nervous system also exhibited impaired LTP, which could be restored, however, by repetitive stimulation. These mice also displayed impaired contextual, but not cued fear conditioning, and impaired memory retrieval in the spatial water maze despite good performance during training (Fleischmann et al. 2003).

In addition to studies using knockout mice, experiments using antisense oligodeoxynucleotides (AS ODNs) also confirmed a role for $c$-fos in memory consolidation. AS ODNs are short (1820 bases) synthetic chains of DNA encoding antisense sequence of a particular IEG mRNA that can be delivered with temporal and regional precision into structures such as the hippocampus. Inside the cell, the AS ODNs base-pair with their target mRNA, block its translation, and increase turnover. Intrahippocampal infusions of AS ODNs against c-fos mRNA impaired consolidation of inhibitory avoidance (Guzowski and McGaugh 1997) and spatial water maze training (Guzowski 2002). Intrahippocampal infusion of $c$-fos AS ODNs also impaired consolidation of socially transmitted food preference (STFP) (Countryman et al. 2005).

The effector IEG Arc (a ctivity-regulated cytoskeletonassociated protein; Lyford et al. 1995; also known as Arg 3.1; Link et al. 1995) has attracted interest in the field of learning and memory for several reasons. Like other IEGs, Arc gene expression is increased dramatically by LTP-inducing stimuli and behavior, and, more importantly, its expression in hippocampus correlates with performance in a hippocampus-dependent task (spatial water maze) (Guzowski et al. 2001). Only principal neurons were found to express $\operatorname{Arc}$ mRNA and protein following behavioral experience in hippocampus, neocortex, and striatum (Vazdarjanova et al. 2006). Following induction, Arc mRNA is rapidly transported to activated portions of dendrites (Steward et al. 1998; Moga et al. 2004), and this targeting, as well as behavioral induction, is dependent on NMDA receptor activation (Steward and Worley 2001). Translation of the dendritically localized Arc mRNA can be regulated by BDNF and NMDA receptor activation (Yin et al. 2002) and involves the mTOR pathway (Takei et al. 2004). Together, these data suggest the necessary mechanisms for Arc to modify the function of discrete synapses in activated neurons.

Interaction of Arc with microtubule associated protein 2 (MAP2) was suggested to play a role in cytoskeleton destabilization in studies of transfected primary neurons (Fujimoto et al. 2004). Such destabilization could be important for dendritic remodeling associated with lasting changes in synaptic efficacy. Another in vitro study suggested that Arc interacts with calciumcalmodulin kinase II (CaMKII), and that this interaction promotes neurite outgrowth in cultured neuroblastoma cells (Donai et al. 2003). Arc was also found in NMDA receptor complexes, consistent with a role in LTP and memory (Husi et al. 2000). In the most detailed account of its cellular function, Arc has been shown to facilitate AMPA receptor endocytosis in cultured neurons via interaction with dynamin and specific isoforms of endophilin (Chowdhury et al. 2006). Accordingly, Arc overexpression reduced APMA receptor-mediated synaptic transmission in organotypic slice culture neurons (Rial Verde et al. 2006). These findings suggested that Arc may mediate homeostatic scaling of synaptic AMPA receptors (Shepherd et al. 2006).

Inhibition of Arc protein expression in dorsal hippocampus by local infusion of antisense oligodeoxynucleotides (AS ODNs) disrupted maintenance of LTP, but it did not affect its induction. In addition, intrahippocampal infusion of Arc AS ODNs strongly impaired consolidation of memory for spatial water maze training, without affecting task acquisition or short-term memory. Control infusion of ODNs with the same nucleotide composition but with no homology with the target RNA (scrambled ODNs) had no effect (Guzowski et al. 2000). Similar findings were reported from mice with genetic ablation of the Arc gene (Plath et al. 2006). The mice showed long-term memory impairments with relatively spared acquisition or short-term memory in several explicit and implicit learning tasks including spatial and cued water maze, contextual and cued fear conditioning, conditioned taste aversion, and novel object recognition. They also displayed impaired long-term plasticity with enhanced early- and absent lateLTP and absent stable long-term depression. Together, these find- 
ings indicate that Arc plays an essential role in the stabilization of activity-dependent synaptic plasticity and synaptic consolidation (Guzowski et al. 2000; Guzowski 2002; Plath et al. 2006).

Although not functionally tested at present, the effector IEG Homer 1a may also play a role in modification of hippocampal synaptic plasticity and memory consolidation. Homer $1 a$ is a synaptically regulated isoform of the Homer 1 gene (Brakeman et al. 1997; Bottai et al. 2002). Neurons expressing Homer $1 a$ following a behavioral experience are the same population that express Arc (Vazdarjanova et al. 2002) - these two dendritic effector proteins are coexpressed in the same neurons following experience. Overexpression of Homer 1a in dissociated hippocampal neuronal cultures decreased the density and size of dendritic spines, the size of PSD-95 clusters, the number of NMDA receptor clusters, and the level of surface AMPA receptors, and also diminished postsynaptic AMPA and NMDA receptor synaptic currents (Sala et al. 2003).

At this point, it is worth emphasizing an important distinction between synaptic and systems consolidation. Generally, the term "memory consolidation" refers to transformation of newly formed memories from an initially weak and disruption-sensitive state into more persistent and permanent long-term memories. This process, however, may occur at several levels. Synaptic consolidation occurs on the level of synapses or neurons, and it results in transformation of short-term memories to long-term memories (hours to days or even months) (McGaugh 2000; Frankland and Bontempi 2005). Systems consolidation occurs between different brain systems, particularly between hippocampus and neocortex, and it results in long-lasting memories (months to lifetime) (Squire and Alvarez 1995). Although primarily implicated in synaptic consolidation, IEGs may act to support continued synaptic strengthening during overtraining, retrieval, or off-line processing in the course of systems consolidation (Ribeiro and Nicolelis 2004). Throughout this review, by "memory consolidation" we mean the synaptic process, unless explicitly mentioning "systems consolidation."

In conclusion, the functional studies targeting RTF IEGs and Arc demonstrate a critical importance of IEG expression for longterm memory formation and implicate IEG expression in coupling neuronal activity with lasting changes in synaptic efficacy underlying long-term memory (Tischmeyer and Grimm 1999; Guzowski et al. 2000, 2001; Jones et al. 2001; Guzowski 2002; Davis et al. 2003). Thus, IEG imaging methods may reveal not only which brain regions are active during a specific behavior, but also which areas might be undergoing neural plasticity.

\section{Regulation of hippocampal IEG expression by behavior and brain systems interactions}

IEGs are induced in the hippocampus after behavioral experience in a novel environment (Arc; Guzowski et al. 1999; Vazdarjanova et al. 2002); in a water maze (Arc, zif268, c-fos; Guzowski et al. 2001); on a radial arm maze (c-Fos; Vann et al. 2000a); or in contextual, but not cued, fear memory retrieval (zif268; Hall et al. 2001). The proportions of Arc-expressing neurons in CA1 and CA3 after exploration of an environment, the selectivity of the activated ensembles to specific spatial contexts (Guzowski et al. 1999; Vazdarjanova and Guzowski 2004), and the reliability of $\operatorname{Arc}$ expression after repeated experience in the same environment (Guzowski et al. 2006) strongly resemble the characteristics of location-specific activity of hippocampal place cells, suggesting that neurons expressing Arc after exploration of an environment are place cells that expressed a firing field in that environment (Guzowski et al. 2004). Both location/context-specific neuronal activity and IEG expression are likely to derive their characteristics from the activity patterns of inputs to the hippocampus.

The hippocampus receives input, either directly or indirectly, from much of the rest of the brain. Highly processed cortical input arrives via the perforant path projection from the entorhinal cortex. The main subcortical input comes to the hippocampus from medial septum via the fornix, and emotional and motivational modulatory input comes from the amygdala (Amaral and Witter 1995; Pikkarainen et al. 1999). Unilateral lesions of entorhinal cortex abolished behavioral induction of Arc expression in both ipsi- and contra-lateral dentate granule cells and to a lesser extent also in the CA3 and CA1 fields (Temple et al. 2003). This finding points to the physiological importance of commissural projections to the dentate gyrus either directly from the contralateral entorhinal cortex or from the mossy cells in the polymorphic layer of the contralateral dentate gyrus (Amaral and Witter 1995). Behavioral induction of Arc reappeared with a time course consistent with reinnervation, but baseline expression remained somewhat reduced (Temple et al. 2003). These data are consistent with the entorhinal cortex providing the major information input to the hippocampus.

Unilateral fornix lesions abolished the behavioral induction of Arc expression only in the ipsilateral DG, CA3, and CA1, but not in the contralateral hemisphere (Temple et al. 2003). Similarly, bilateral lesions of the fornix abolished behavioral induction of Arc expression in all three subfields bilaterally and prevented spatial, but not cued, water maze learning (Fletcher et al. 2006). In the same study, the fornix lesions did not affect baseline expression or induction of Arc expression by high-frequency stimulation of the medial perforant pathway. In other studies, fornix lesions were also shown to block learning-dependent increases in the phosphorylation of CREB (Taubenfeld et al. 1999), increases in c-Fos protein (Vann et al. 2000b), and expression of C/EBP $\beta$ and $\delta$ mRNA (Taubenfeld et al. 2001) in the hippocampus. Fornix lesions eliminate theta rhythm in dorsal hippocampus (Rawlins et al. 1979), severely disrupt hippocampusdependent learning, and alter, but do not eliminate, locationspecific activity of hippocampal place cells (pyramidal neurons in CA3 and CA1, also called complex-spike cells; Miller and Best 1980; Shapiro et al. 1989). Nonselective lesions of medial septum eliminate hippocampal theta (Rawlins et al. 1979), impair spatial working memory on the radial arm maze, and mildly alter the physiology of hippocampal place cells without changing their location specificity (Leutgeb and Mizumori 1999). Inactivation of the medial septum also eliminated hippocampal theta rhythm, disrupted spatial learning (Mizumori et al. 1990), and reduced (50\%) place cell activity of CA3 neurons, leaving CA1 place cells intact (Mizumori et al. 1989). On the other hand, selective cholinergic lesions of the medial septum by 192 IgG-Saporin, which reduces but does not eliminate theta (Lee et al. 1994), spared water maze learning and behavioral induction of Arc expression by exploration of a novel environment (Fletcher et al. 2007). Together with our observation that inactivation of medial septum abolishes the behavioral induction of Arc expression in CA1 and CA3 subregions of the hippocampus (T. Miyashita, S. Kubik, and J.F. Guzowski, unpubl.), these findings support the conclusion that hippocampal theta rhythm is critical for behavioral induction of Arc expression. In the absence of theta rhythm, desynchronized activity is not able to trigger plastic changes in synaptic transmission necessary for activity-dependent IEG transcription and memory consolidation. In this sense, Arc expression may not automatically follow neuronal activity such as expression of a place field, which, unlike Arc expression, is maintained in the absence of theta.

The link between long-term memory formation and Arc expression in the hippocampus suggests that Arc is involved in 
learning-related plasticity rather than in mere neuronal activity. On the other hand, Arc RNA is faithfully induced by repeated exploration of a familiar environment over many days, and only declines dramatically after repeated exposures during a single day (Guzowski et al. 2006). These findings may suggest that hippocampal neurons continue to update their representations (and express $A r c$ ) during repeated exposures to a familiar environment over multiple days. Alternatively, sustained increases in Arc protein level may be required for learning, whereas transient Arc transcription may simply reflect neuronal activity. In support of this view, memory-enhancing $\beta$-adrenergic activity in the basolateral amygdala (BLA) increased, and memory-impairing BLA blockade with lidocaine decreased, Arc protein level in dorsal hippocampus without affecting Arc mRNA levels in rats trained in inhibitory avoidance (McIntyre et al. 2005). In support of the conclusion that IEG expression in hippocampal neurons, whether at mRNA or protein levels, can be modulated by activity in the BLA, Huff and colleagues demonstrated that BLA inactivation with muscimol attenuated increases in $A r c$ and $c$-fos mRNA in hippocampus after contextual fear conditioning, but not after context exploration (Huff et al. 2006). It should be noted that a critical difference between the Huff and McIntyre studies was the time of BLA inactivation, with Huff et al. (2006) using pre-training infusions and McIntyre et al. (2005) using post-training infusions. In this context, it is important to remember that the term "IEG activation" must be examined carefully as it does not describe a unitary molecular process, but rather a regulated series of processes including transcriptional regulation, post-transcriptional processing of mRNA, mRNA trafficking and targeting, translational regulation, post-translational regulation, and control of protein degradation.

In conclusion, we interpret the available findings to suggest that the combination of place cell activity associated with expression of a firing field, NMDA receptor activation, and theta rhythm provides a sufficient signal to activate IEG transcription in the hippocampus, but that neuromodulatory inputs, such as those from the amygdala, can alter downstream steps in functional IEG expression.

\section{Using immediate-early genes to map and dissect hippocampal subregional functions}

As discussed above, IEG expression is believed to mediate learning-related changes in synaptic efficacy. Therefore the levels of IEG transcription (mRNA) are believed to faithfully reflect strong neuronal activation. This idea formed the basis of IEG imagingusing IEG expression to map neural activity in brain circuits. The major advantage of this approach is the ability to evaluate activity simultaneously in many different brain regions with cellular resolution.

\section{Conventional IEG imaging}

In its conventional form, IEG imaging uses either immunohistochemistry or in situ hybridization to detect IEG protein or mRNA, respectively. Densitometry of in situ autoradiography provides relative signal differences between brain regions such as between CA3 and CA1 and between different behavioral conditions (Hess et al. 1995a,b; Gall et al. 1998; Kelly and Deadwyler 2002, 2003). Fluorescent or chromagenic immunohistochemical detection allows comparing proportions of IEG-positive cells (Colombo et al. 2003; Weitemier and Ryabinin 2004). As noted above, IEG protein levels are subject to both transcriptional and post-transcriptional regulation. In this sense, IEG imaging studies that detect RNA or protein provide complementary, not identical, information, and the detection method used should be kept in mind when interpreting the findings from IEG studies. Be- cause mRNA levels are more directly connected to the inducing event, IEG RNA detection methods provide a more direct readout of neuronal activation. In addition, the half-life of IEG mRNA is also shorter, yielding higher signal-to-noise ratio for some IEGs like Arc or zif268 (Guzowski 2002). In contrast, steady-state protein levels reflect integration of multiple cellular processes and modulatory signals, and, as such, may be more closely associated with neuroplastic changes engaged by distinct behaviors.

Doubts about the specificity of the IEG response to taskrelated learning stimulated the use of nonlearning controls. However, matching controls for all behavioral parameters except learning in order to subtract the "learning signal" brings significant problems. For example, latent learning occurring in the control animals (Rapp et al. 1987; Packard and McGaugh 1996) may preclude finding significant learning-related increase in IEG expression (Guzowski 2002), particularly in the hippocampus, which has been implicated in automatic encoding of ongoing experience (Morris and Frey 1997). Indeed, spatial, (hippocampus-dependent) and cued (hippocampus-independent) learning in the water maze caused equivalent increases in hippocampal expression of IEGs Arc, zif268, and c-fos (Guzowski et al. 2001). This problem is also known in human fMRI studies where substantial activity in the hippocampal region during control "rest" states obscures specific signal during task conditions (Stark and Squire 2001).

Moreover, changes in which neurons are active, rather than how many of them, are likely to carry specific information within neural codes. Conventional IEG imaging methods cannot resolve this problem because they can only detect IEG expression at a single time point, limiting behavioral comparisons to between-subject design. Learning-specific signal obtained in this way may be easily overlooked in regions with high coding sparseness (low proportion of simultaneously active neurons) such as dentate gyrus or CA3. This may be the reason that some conventional IEG imaging studies reported learning-related changes only in CA1, but not CA3 or dentate gyrus (Hall et al. 2001; Frankland et al. 2004; Maviel et al. 2004).

\section{catFISH}

The catFISH technique (cellular compartment analysis of temporal activity by fluorescence in situ hybridization; Guzowski et al. 1999) circumvented several of the problems noted above by enabling assessment of activity of the same neurons during two distinct behavioral epochs. This advance was achieved using the dynamic regulation of transcription of the IEG Arc (Link et al. 1995; Lyford et al. 1995) and rapid translocation of its mRNA from nucleus to soma and dendrites (Steward et al. 1998; Guzowski et al. 1999). Briefly, ongoing transcription of Arc RNA induced by the behavioral epoch immediately (2-10 $\mathrm{min}$ ) preceding the animal's death can be detected as bright intranuclear foci (Arc-INF), whereas activation induced 20-25 min earlier can be seen as diffuse somatodendritic staining (Arc-cyto). A variant of this method, Arc/Homer 1a catFISH, combines hybridization to two IEGs, Arc and Homer 1a, which are coinduced in the same population of neurons (Vazdarjanova et al. 2002). The activity at the recent time point is again detected as Arc INF, but the activity at the remote time point is now detected as Homer $1 a$ intranuclear foci (H1a-INF). The different time course of detection of the two IEGs arises from using a riboprobe for the 3' UTR (untranslated region) of the primary transcript of Homer $1 a$ (40 kb from the start site), which does not occur until $25 \mathrm{~min}$ after the inducing episode because of the limited elongation rate of the RNA polymerase II (Bottai et al. 2002). Therefore, neurons active during 2-10 min before the animal's death show Arc-INF, whereas neurons active $\sim 25-30 \mathrm{~min}$ earlier will display Arc-cyto and/or 
$\mathrm{H1a}$-INF. The INF signal as a measure of active IEG transcription gives catFISH better temporal resolution compared to steadystate mRNA detection methods (Guzowski 2002). The robust INF signal also increases the signal-to-noise ratio and can be analyzed even in structures with high cellular density such as CA1, where quantifying the diffuse cytoplasmic signal may be difficult (Vazdarjanova et al. 2002).

The ability to infer neural activity of the same neurons at two different time points allows catFISH to quantify the degree of overlap between neuronal ensembles activated by two different experiences. The same neuronal ensembles in CA1 were activated by repeated experiences in the same environment, whereas widely different ensembles were active in two different environments (Guzowski et al. 1999). This finding demonstrated that IEG expression in CA1 during exploration reflects processing of specific information about the behavioral episode, rather than general features of the behavioral experience such as increased stress, motor activity, or arousal. As such, the specificity of IEG response could not have been recognized with conventional IEG imaging techniques.

\section{Limitations of IEG imaging approaches}

As with other methods to detect changes in neural function (e.g., single unit recording, fMRI, etc.), it is important to remember that activity within a structure does not necessarily dictate functional requirement for a specific behavior. For example, increased IEG expression in the hippocampus was observed in overtly hippocampus-independent tasks (odor discrimination [Hess et al. 1995a,b], lever pressing [Kelly and Deadwyler 2002, 2003], and delay fear conditioning [Weitemier and Ryabinin 2004]), suggesting that the hippocampal IEG expression reflects incidental encoding, which occurs even when it is not required for successful behavior (Rapp et al. 1987; Packard and McGaugh 1996; Morris and Frey 1997). Consistent with this idea, hippocampal Arc, c-fos, and zif268 RNA levels were elevated after training in spatial as well as cued water mazes (Guzowski et al. 2001). The Arc levels correlated with performance in the spatial, but not the cued training. This finding parallels the fact that the spatial version of the water maze depends on hippocampal function, whereas the cued version does not (Morris et al. 1982). A related finding was reported by Colombo and colleagues: Transient increases in pCREB and c-Fos were found in the hippocampus of rats trained on both place and cued versions of a cross-maze task, but these changes were sustained $1 \mathrm{~h}$ after training only in the placetrained rats (Colombo et al. 2003). These studies demonstrate that IEG expression reflects information processing in the hippocampus during behavior, which may be task relevant or irrelevant (Guzowski 2002). In conclusion, IEG imaging studies can identify candidate structures associated with a behavior, but local interventions such as region-specific disruption of IEG expression (see below) are needed to confirm a necessary role for those structures.

\section{Genetic ablation and knockdown strategies}

Correlative IEG imaging is not the only way IEGs may be used to investigate hippocampal circuit function. As IEGs do not have any known direct effects on basal neurotransmission, but do impact synaptic plasticity, methods to knock IEG expression out or down provide a powerful means to investigate the role of specific hippocampal subregions in distinct components of behavior. These methods could include subregional knockout using the loxP-CRE transgenic system (Nakazawa et al. 2002, 2003; Cravens et al. 2006), local injection of CRE-containing viral vectors into a subregion in a "floxed" transgenic mouse line (Rajji et al. 2006), local injection of a viral vector for siRNA-mediated knockdown of gene expression, or local infusion of antisense oligodeoxynucleotides (AS ODNs) (Guzowski et al. 2000) to inhibit translation of an IEG of interest. Although these methods have been used to assess the contribution of NMDA receptors to CA3 function (Nakazawa et al. 2002, 2003; Cravens et al. 2006; Rajji et al. 2006), the behavioral consequences of targeted knockout/ knockdown of a specific IEG in CA3 has not yet been reported. Thus, these approaches belong mostly to the domain of "future studies" at present.

\section{IEG imaging studies of hippocampus in memory}

\section{Hippocampus and spatial memory}

The hippocampus is connected to other structures in the brain forming higher-order circuits. Studies mapping decreases in c-Fos expression in rat brains following lesions of the fornix (Vann et al. 2000b), the anterior thalamic nuclei (Jenkins et al. 2002a,b), or the hippocampus (Jenkins et al. 2006; Albasser et al. 2007) pointed to several interconnected structures including the hippocampus, the subicular complex, the anterior thalamic nuclei, and the retrosplenial, entorhinal, anterior cingulate, and postrhinal cortices. The suggested function of this circuit was to provide spatial context for structural learning and episodic memory (Aggleton and Pearce 2001). In support for the role of the hippocampus in spatial processing, c-Fos activity in the hippocampus increased with spatial complexity on a radial arm maze (Vann et al. 2000a). Novel spatial rearrangement of familiar visual stimuli increased the number of c-Fos-positive nuclei in the hippocampus (Wan et al. 1999; Jenkins et al. 2004), whereas exposure to novel individual items did not (Wan et al. 1999). The increase was most prominent in CA1, whereas the dentate gyrus and subiculum displayed a decrease in c-Fos activity (Wan et al. 1999). On the other hand, Jenkins et al. (2004) found equivalent increases across hippocampal subregions (CA1, CA3, dentate gyrus) in the most rostral portion of the hippocampus, but no effect in subiculum or remaining portions of the hippocampus (Jenkins et al. 2004). Novel combinations of familiar visual cues in familiar locations attenuated induction of c-Fos activity in the retrosplenial cortex and the CA1 of the dorsal hippocampus with no change in the CA3, dentate gyrus, or ventral hippocampus (Amin et al. 2006). However, no effects of cue recombination were found on the expression of Zif268 (Amin et al. 2006). In addition, increased zif268 mRNA expression in CA1 was observed following retrieval of contextual, but not cued, fear conditioning (Hall et al. 2001).

Although these studies yielded conflicting results concerning differences between the hippocampal subregions, they support a role of the dorsal hippocampus in spatial and contextual learning and memory, in agreement with aforementioned studies (Guzowski et al. 1999, 2000, 2001; see above). They are also consistent with the idea that the hippocampus is a part of a "configural" or "structural" learning and memory system including fornix, anterior thalamic nuclei, mamillary bodies, and retrosplenial cortex (Aggleton and Pearce 2001), which may form the core of a context-rich episodic memory system (Aggleton and Brown 1999; Winocur et al. 2007).

\section{Memory acquisition, consolidation, and retrieval}

Hippocampal subregions have been suggested to functionally segregate between processes of memory acquisition, consolidation, and retrieval. Studies using selective lesions of hippocampal subregions suggested that CA3 is preferentially involved in acquisition and CA1 in retrieval of memory for contextual fear (Lee and Kesner 2004b). Similarly, disconnection between DG and CA3 disrupted encoding, not retrieval, of spatial navigation tasks (Hebb-Williams maze; Lee and Kesner 2004a; Jerman et al. 2006). 
High-resolution fMRI revealed that regions "early" in the hippocampal circuit (DG, CA3, and CA2) were active during episodic memory formation, whereas regions "later" in the circuit (subiculum) were active during recollection (Eldridge et al. 2005). Subregion-specific infusions of the NMDA receptor antagonist APV suggested that NMDA receptors in CA3 are involved in updating spatial memory in a non-matching-to-place task on a radial arm maze, whereas NMDA receptor function in CA1/DG is primarily involved in maintenance of memory over longer delays (Lee and Kesner 2002). Mice with CA3-specific genetic ablation of the NR1 subunit of the NMDA receptor showed an impairment in a spatial working memory water maze task (delayed matching to place, DMP) and impaired spatial tuning of CA1 place cells during initial exposure to a novel environment (Nakazawa et al. 2003). In a different study, these mice also displayed transient impairment of contextual memory after a brief, but not after an extended exposure (Cravens et al. 2006). Local deletion of the NR1 subunit in CA3 in $~ 30 \%$ of dorsal hippocampus disrupted learning of paired associations if both components (an odor and a context) were novel, but not expression of learned associations, context discrimination, or learning associations of familiar components (Rajji et al. 2006). These studies suggested that CA3, via its NMDA-dependent plasticity, is involved in rapid, one-trial encoding of complex associations involved in spatial or contextual stimuli.

Greater $c$-fos mRNA expression was found in CA3 than in CA1 during initial acquisition of an odor discrimination task, but it was equivalent in rats that only learned a nose-poking response for water reward (Hess et al. 1995a). Interestingly, whereas odor discrimination per se does not depend on the hippocampus (Kaut and Bunsey 2001; Jonasson et al. 2004), the nose-poking protocol required alternating between multiple nose-poking sites, somewhat resembling hippocampus-dependent alternation (Olton et al. 1979; Aggleton et al. 1986). In a follow-up study (Hess et al. 1995b), rats that only explored the testing environment for the first time showed greater $c$-fos expression in all hippocampal fields than rats overtrained in the odor discrimination. Unlike in the previous study, the c-fos expression was highest in CA1 in both groups (Hess et al. 1995b). These patterns of CA1 or CA3 dominance were suggested to reflect different modes of hippocampal function. The CA3 dominance observed during initial odor discrimination learning may be associated with switching between associative memory retrieval and new learning in CA3. Alternatively, it may reflect suppression of pre-potent responses such as the previously learned nose-poking response (Hess et al. 1995a; Gall et al. 1998). The CA1 dominance observed during exploration and overtrained discrimination may be associated with ongoing spatial processing. Parallel functional modes manifested as different balance of activation between the hippocampal subfields might reflect functional dissociation between memory and anxiety, but the majority of the available evidence place this functional dissociation along the septotemporal hippocampal axis (Bannerman et al. 2004; see "Analysis of CA3/CA1 Ensemble Dynamics Using Catfish" section, below).

A transient learning-specific increase in Arc mRNA expression in CA1 and CA3 was shown in rats performing an operant lever-pressing task (Kelly and Deadwyler 2002, 2003). The Arc activity was generally larger in CA1 than CA3, and it was more persistent in CA1 compared to home cage controls (Kelly and Deadwyler 2003), but not pseudotrained controls (Kelly and Deadwyler 2002). These findings somewhat resemble the CA1 dominance during exploration in the study of Hess et al. (1995b). The more transient activation in CA3 is consistent with its role in initial learning. It is not clear, however, how the lever-pressing task relates to hippocampal function and whether the activity observed in the hippocampus reflects formation of memory for the task, incidental spatial encoding, or an independent process of "automatic recording of attended experience" (Morris and Frey 1997).

The above IEG imaging studies seem to suggest that the CA3 subregion of the hippocampus is preferentially involved in initial learning. While this is in agreement with lesion (Lee and Kesner 2004a,b; Jerman et al. 2006) and fMRI data (Eldridge et al. 2005), there are several constraints to this interpretation. First, latent hippocampus-dependent learning of a spatial location can occur as animals are trained in hippocampus-independent tasks (Rapp et al. 1987; Packard and McGaugh 1996). Second, the use of behavioral tasks without an obvious requirement for hippocampal function renders it difficult to interpret how increased activation in CA3 is involved in learning the task. Third, other IEG studies (Gusev et al. 2005; Smith et al. 2007) reported persistent, rather than transient increase in IEG expression in CA3. Fourth, all of the above studies used conventional imaging methods with limitations relating to control groups and between-subject design as mentioned above. It is possible that the specific contributions of different subregions to hippocampal function are interdependent and orthogonal to the stages of memory formation so that the subregions are differently activated by different task demands rather than during different stages of memory. In conclusion, conventional IEG studies as a whole have been equivocal with regard to specific subregional functions in different stages of memory. Instead, the IEG activity observed in the hippocampus in hippocampus-independent tasks (Hess et al. 1995a,b; Guzowski et al. 2001; Kelly and Deadwyler 2002, 2003) supports the idea that hippocampus engages in continuous recording of ongoing experience (Morris and Frey 1997).

\section{IEG imaging studies of systems consolidation}

Several studies have shown elevated IEG expression in the hippocampus following recent, but not remote, memory retrieval in support of a time-limited involvement of the hippocampus in declarative long-term memory (standard theory of systems consolidation; Squire and Alvarez 1995). Increased zif268 RNA was found in CA1 of rats tested for retrieval of contextual conditioned fear $24 \mathrm{~h}$, but not $28 \mathrm{~d}$, after training (Hall et al. 2001). C57BL/6 mice trained in the contextual fear paradigm showed increased levels of Zif268 and c-Fos proteins in the CA1 after recent ( $1 \mathrm{~d}$ ) but not remote ( $36 \mathrm{~d})$ memory retention test relative to nonshocked controls (Frankland et al. 2004). Zif268 expression was increased after recent (1 d), but not remote (30 d), memory test in the CA1 of mice trained in a reference memory task on a five-arm radial maze relative to nonlearning controls. Lidocaine infusion into the hippocampus abolished the Zif268 immunoreactivity in CA1 and impaired retrieval of the recent, but not remote memory (Maviel et al. 2004). Unfortunately, this report does not make clear if the task could have been solved using a response strategy, in which case a shift from hippocampal-dependent place to caudate-dependent response strategy could be expected to occur between the recent and remote time points (Packard and McGaugh 1996). In addition, persistent Zif268 activation was observed in hippocampus $30 \mathrm{~d}$ after training in a working memory paradigm (Maviel et al. 2004), indicating that a lack of demand for hippocampal function could have caused the diminished hippocampal activation in the reference memory version of the task.

Arc mRNA expression in CA1, CA3, DG, subiculum, and entorhinal cortex all along the septotemporal axis of the hippocampus was compared in rats trained in the water maze and tested for retention either $24 \mathrm{~h}$ or 1 mo later in three nonrewarded probe trials (Gusev et al. 2005). Both groups showed robust place responses with different, but nonsignificant trends. 
Rats in the 24-h retention group were slightly worse in the third probe, whereas animals at the long retention interval actually improved over the three probes, perhaps suggesting some kind of "reminder" effect. CA3 displayed the most persistent Arc learning-specific signal at the remote retention test, as compared to swimming controls yoked for time. This learning-specific signal disappeared completely in CA1 and ventral hippocampus. Generally, the learning-specific signal dramatically declined between recent and remote retention interval in all hippocampal subfields. This result was interpreted as a decline in hippocampal involvement in declarative memories over time, in support of the standard theory of systems consolidation (Gusev et al. 2005).

The interpretations of these IEG studies supporting systems consolidation, however, have some serious limitations. First, memory for the water maze does not undergo systems consolidation because hippocampal dysfunction always results in impairment (Sutherland et al. 2001; Clark et al. 2005; Martin et al. 2005; Broadbent et al. 2006; Teixeira et al. 2006). It has been argued that this is also the case for contextual fear and possibly even other types of hippocampus-dependent learning because hippocampal lesions impaired recent as well as remote memory for contextual fear (Lehman et al. 2007). The most parsimonious account of these discrepant results suggests that the spared contextual fear at remote retention intervals (Kim and Fanselow 1992; Anagnostaras et al. 1999; Hall et al. 2001; Frankland et al. 2004) is actually a consequence of forgetting leading to generalization of fear to nontraining contexts (Rudy et al. 2005). Preexposure to the training context prevented generalization of fear to a nontraining context during the test, demonstrating that poor contextual memory was really the cause of generalization of the fear response (Biedenkapp and Rudy 2007; Wiltgen and Silva 2007). Second, the increase in learning-specific signal (see discussion above) observed after recent memory retrieval (Frankland et al. 2004; Maviel et al. 2004) may reflect an ongoing process of synaptic consolidation associated with recent learning. However, this process should have been completed by the time of the remote memory recall, and therefore IEG expression was not required. Alternatively, the transitory increase in activity observed in CA1 may be a correlate of new learning, whereas remote memory retrieval is mediated by the persistent activity in CA3. Slower development of hippocampal representation in the nonreinforced control groups may be another explanation of the transient "learning-specific" signal.

In summary, the studies on systems consolidation suffer from the pitfalls inherent in conventional IEG imaging methods and basic experimental design issues (mentioned above), undermining their conclusions. More careful use of advanced IEG approaches, with better experimental design, will be needed to study how hippocampal memory traces change over the course of time.

\section{IEG studies of dissociation between memory and anxiety along the septotemporal axis of the hippocampus}

Similarities between effects of hippocampal lesions and anxiolytic drugs stimulated the hypothesis that the hippocampus plays a role in behavioral inhibition and control of anxiety by increasing the value of negative reinforcement in order to inhibit prepotent or inappropriate responses (Gray and McNaughton 2000; Chan et al. 2001; Deacon et al. 2002). In its orthodox form (Davidson and Jarrard 2004), this view largely ignores most data on hippocampal involvement in memory, particularly studies of amnesic patients after hippocampal damage (Scoville and Milner 1957; Squire et al. 2004). In reconciliation of these discordant views, functional dissociation along the septotemporal axis of the hippocampus has been suggested based on differences in anatomical inputs and differential effects of dorsal and ventral hippocampal lesions (Bannerman et al. 2004). Lesions of the dorsal, but not ventral, hippocampus impaired spatial memory in the water maze (Moser et al. 1995; Moser and Moser 1998a,b) and both reference and working spatial memory on the radial arm maze (Pothuizen et al. 2004; McDonald et al. 2006). On the other hand, ventral, but not dorsal, lesions attenuated unconditioned fear (Kjelstrup et al. 2002), various measures of anxiety (Bannerman et al. 2003, 2004; Pentkowski et al. 2006), and inhibitory associations (McDonald et al. 2006), but not spatial learning (Moser et al. 1995; Moser and Moser 1998b; Bannerman et al. 2003). Administration of the NMDA receptor antagonist AP-5 into ventral, but not dorsal, hippocampus attenuated anxiety tested on the elevated plus maze (Nascimento Häckl and Carobrez 2007). In accordance with this view, a spatial scaling gradient along the septotemporal axis of the hippocampus was found in spatial firing of CA1 neurons (Maurer et al. 2005), and a parallel trend was observed also in the entorhinal cortex (Sargolini et al. 2006). Neurons at the septal (dorsal) extreme showed the smallest firing fields and greatest spatial resolution, which decreased toward the temporal pole of the hippocampus. This is consistent with detailed representations in the dorsal hippocampus being critical for precise spatial navigation, whereas the coarse representation in the ventral hippocampus relates primarily to nonspatial aspects of behavior.

In support of functional dissociation along the septotemporal axis, spatial rearrangement (Jenkins et al. 2004) or novel configuration of familiar stimuli (Amin et al. 2006) increased the number of c-Fos-positive neurons in the dorsal, but not the ventral, hippocampus. Similarly, training in a spatial working memory task on a radial arm maze induced greater c-Fos activation in the dorsal hippocampus (Vann et al. 2000a). Also, robust behavioral induction of Arc expression by exploration of a novel environment (Guzowski et al. 1999) or by training in a water maze (also c-fos and zif268; Guzowski et al. 2001) was observed in the dorsal hippocampus.

Exposure to social defeat increased the number of c-Fospositive cells in all fields of both the dorsal and ventral hippocampus (Calfa et al. 2007). Inactivation of the ventral, but not the dorsal, hippocampus with lidocaine attenuated excessive anxiety in the defeated rats. Infusion of a glucocorticoid receptor antagonist into lateral septum prevented the increase in the number of Fos-positive cells especially in the ventral hippocampus (Calfa et al. 2007). Increased numbers of Fos-positive cells were observed in the ventral, but not the dorsal, hippocampus after acquisition (CA3 and dentate gyrus) and $48 \mathrm{~h}$ recall (CA3 only) of socially transmitted food preference (STFP) (Smith et al. 2007). The STFP task is based on inhibition of hyponeophagia, novelty-associated reduced food consumption, which is an innate rat behavior and is used as a measure of anxiety. In this way, it can be linked to the hippocampus, particularly its ventral portion within the theoretical framework of hippocampal involvement in behavioral inhibition and anxiety (Gray and McNaughton 2000; Chan et al. 2001; Bannerman et al. 2004). In conclusion, these IEG studies support the idea of functional differentiation between memory and anxiety along the septotemporal axis of the hippocampus.

\section{Analysis of CA3/CA1 ensemble dynamics using catFISH}

Structural differences between hippocampal subfields had been recognized already by early (Ramón y Cajal 1893; Lorente de No 
1934) as well as modern neuroanatomists (Amaral and Witter $1989,1995)$. Ideas of their differential functions were formulated in numerous computational models (Marr 1971; McNaughton and Morris 1987; McClelland et al. 1995; Rolls and Treves 1998; O'Reilly and Rudy 2001; Rolls and Kesner 2006). Despite this history, demonstrations of functional differentiations within the hippocampus remained scarce, until recently. Rats with selective lesions of the CA3 region were impaired in spatial discrimination across all spatial separations (Gilbert and Kesner 2006), whereas rats with lesions of the dentate gyrus showed a separation gradient, and rats with CA1 lesions performed at control levels (Gilbert et al. 2001). These results suggested that the dentate gyrus is responsible for spatial pattern separation, and the CA3 is necessary for spatial working memory encoding. Mice with NMDA receptor subunit NR1 knockout specific to pyramidal neurons in CA3 showed memory impairment when only a subset of the original training cues was present, supporting the idea that CA3 performs pattern completion in an autoassociative network (Nakazawa et al. 2002). Accordingly, rats with selective lesion of the CA3 showed impairment in spatial pattern completion in a delayed matching-to-place task (Gold and Kesner 2005).

Early recording studies of hippocampal place cells found few differences between CA3 and CA1 place fields (Muller et al. 1987), with experimenters sometimes even pooling the data
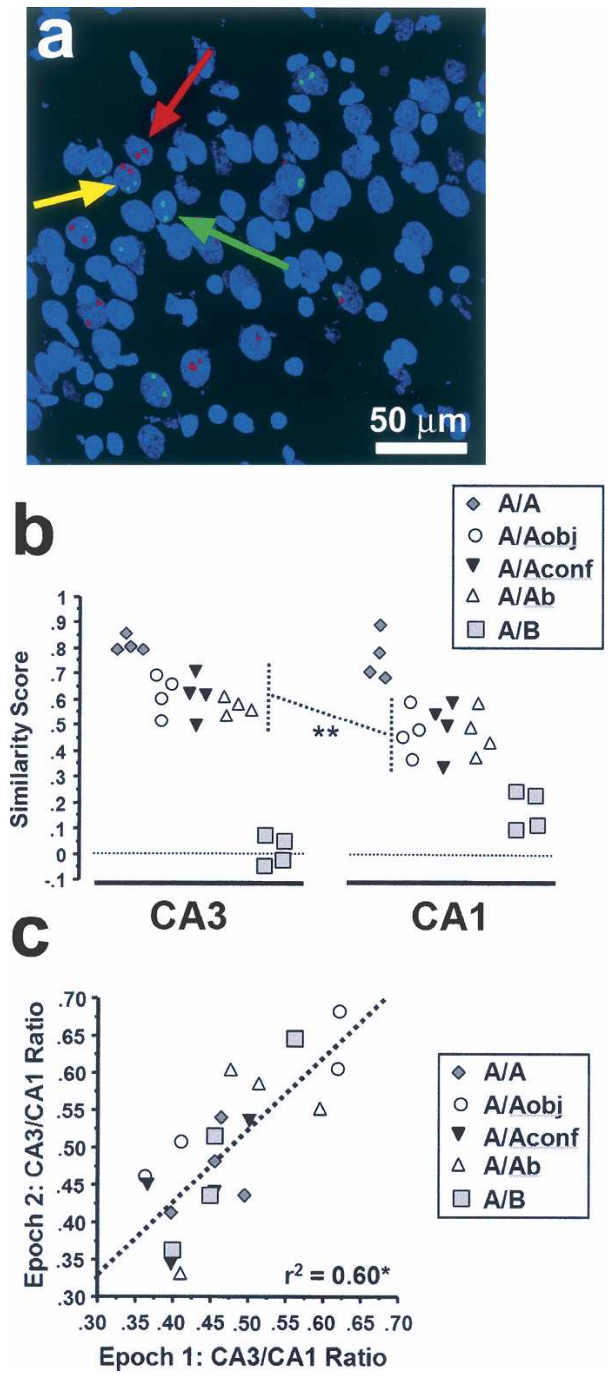

(Quirk et al. 1990; Bostock et al. 1991). Advances in large-scale multiunit hippocampal recordings made it possible to observe differences in spatial population codes between DG, CA1, and CA3, but conflicting results were generated. Changes in an environment were more pronounced in firing of CA1 place cell ensembles than in CA3 ensembles (Lee et al. 2004), but different environments were represented more similarly in CA1 than in CA3 (Leutgeb et al. 2004).

Reconciliation of the conflicting data came from an IEG study comparing neuronal ensembles in CA3 and CA1 active during two behavioral experiences using Arc/Homer 1a catFISH (Fig. 1A; Guzowski et al. 2004; Vazdarjanova and Guzowski 2004). Rats explored a novel environment in a 6-min session (epoch 1), and after a 20-min interval, they received a second ex-

Figure 1. Imaging $C A 3$ and $C A 1$ neuronal ensemble activity following exposure to two environmental contexts. In this study, rats were given two 6-min exposures to two environments (epoch 1 and epoch 2), separated by $20 \mathrm{~min}$. Each of the environments was defined by a unique combination of local features (objects in a fixed configuration within the enclosure of the environment) and distal features (defined by the room, such as posters on the walls, lighting differences, etc). Environments A and $B$ were designed to be as dissimilar as possible, with different enclosure geometries (Environment A was square, Environment B was circular), wall heights, different local objects within the environment (and in a different geometrical configuration), and different distal features, as the two environments were in different rooms. Environment $A^{\prime}$, for the purposes of this review, is the combination of three minor modifications to environment A: (Aobj) a change of the identity of the local objects; (Aconf) a change in the configuration of the same objects; (Ab) moving the exact local environment to a different room. The ensemble activity for both $C A 3$ and $C A 1$ in each of the groups comprising the $A / A^{\prime}$ group was different from groups $A / A$ and $A / B$, but not with each other, justifying their collapse into a single group. The sequence of the rats' exposure to environments in epochs 1 and 2 defined the behavioral group, with the $\mathrm{A} / \mathrm{A}$ group being exposed to the same environment twice, the $\mathrm{A} / \mathrm{A}^{\prime}$ group being exposed to two similar environments, and the $A / B$ group being exposed to two completely different environments. $(A)$ Confocal projection image of $\mathrm{Arc} / \mathrm{Homer}$ catFISH in area CA3 from an A/B rat; (red) $\mathrm{ArC}$ RNA; (green) H1a RNA; (blue) nuclei. (Green arrow) Points to an $\mathrm{H1a+}$ neuron, which was activated only during behavioral epoch 1; (red arrow) points to an Arc+ neuron, which was activated only during behavioral epoch 2; (yellow arrow) points to an Arc/H1a double+ neuron that was activated in both epoch 1 and epoch 2 . For quantitative analyses of image stack data, only putative neuronal nuclei, characterized by their large volume and relatively diffuse staining with DAPI, were assessed for the presence or absence of intranuclear foci for Arc or H1a. (B) Analysis of similarity scores of rats from the different behavioral groups. Similarity scores are a single measure derived from the raw staining class data in which individual neuronal nuclei are classified as $\mathrm{ArC}+\mathrm{H} 1 \mathrm{a}+\mathrm{ArC} / \mathrm{H} 1 \mathrm{a}$ double+, or negative. The derivation of the similarity score is described in detail elsewhere (Vazdarjanova and Guzowski 2004) and provides a normalized measure of overlap between neuronal ensembles active in the two behavioral sessions. A similarity score of 1 indicates a complete overlap of the neuronal ensembles activated by epoch 1 and epoch 2, whereas a similarity score of 0 indicates no overlap beyond that predicted by chance. Each symbol denotes data from an individual rat. In both CA3 and $C A 1$, the similarity scores from rats of the $A / A^{\prime}$ group were significantly different from those of the $A / A$ and $A / B$ groups $(P<0.0001)$. Notably, the similarity score of the $A / A^{\prime}$ rats was greater in $C A 3$ as compared to CA1 $(P=0.001)$. Conversely, the similarity score in the A/B condition in CA1 was significantly different from chance $(P=0.02)$ and greater than in CA3 $(P=0.015)$. Note the discontinuous pattern of overlap in the $A / A$, $A / A^{\prime}$, and $A / B$ groups for region $C A 3$ as compared to region $C A 1$, which is more graded and linear in nature. $(C)$ The within-rat ratio of CA3 to CA1 activity was strongly correlated across behavioral epochs and was not influenced by the nature of epoch 2 . The fact that the CA3 and CA1 activity was not correlated across rats (data not shown), but that the CA3/CA1 within-rat ratio was correlated across sessions, suggests that the balance of CA3 to CA1 activity is highly specific to each individual rat. This individual difference in the intrinsic hippocampal CA3:CA1 network dynamic could play a role in determining the capacity of individuals for spatial navigation or mnemonic functions. This figure is based on data and figures from Vazdarjanova and Guzowski (2004) (Copyright 2004 by the Society for Neuroscience). 
ploration session (epoch 2). Nearly the same ensembles were active in the CA3 of rats exposed to the same environment twice (A/A condition; Fig. 1B), but dramatically different CA3 ensembles were active in two different environments (A/B condition; Fig. 1B). The response of CA3 ensembles was relatively insensitive to minor changes of the environment (A/ $\mathrm{A}^{\prime}$ condition; Fig. 1B). These changes included different objects (Aobj), different spatial configuration of familiar objects (Aconf), or different distal stimuli $(\mathrm{Ab})$, and because the ensemble responses to those changes did not differ, they were pooled into the minor change category $\left(\mathrm{A} / \mathrm{A}^{\prime}\right)$. The $\mathrm{CA} 1$ ensembles were also highly similar in the same environments (A/A condition; Fig. 1B), but in contrast to $\mathrm{CA} 3$, they were not entirely independent in different environments (A/B condition; Fig. 1B), suggesting that the CA1 ensembles represented sensory similarities between the environments or handling procedures. The CA1 ensemble responses across different conditions (A/A, A/A', A/B) were more linearly related to the changes in the environment (Fig. 1B). The CA3 ensembles activated in different environments were statistically independent, indicating orthogonalization by an active pattern separation process, whereas a pattern completion process led to reactivation of the same representation if the change was sufficiently small. Dynamic tension between these two processes in CA3 was responsible for the nonlinear responses of CA3 ensembles (Fig. 1 B; Vazdarjanova and Guzowski 2004). A competitive neural network in the dentate gyrus was most likely responsible for the pattern separation process (Rolls and Treves 1998). The sudden orthogonalization of CA3 representations resembles global remapping in unit recording studies, whereas more subtle differences may be encoded by rate remapping without changing the encoding ensemble (Leutgeb et al. 2005). The proportions of active neurons corresponded to the electrophysiological findings (Guzowski et al. 2004; Vazdarjanova and Guzowski 2004) and to the theoretical models (Marr 1971; Rolls and Treves 1998). The sparseness was greater in CA3 $(\sim 18 \%)$ than in CA1 $(\sim 35 \%)$, but far greatest in the dentate gyrus, where exploration induced $\operatorname{Arc}$ in only $\sim 2 \%$ of granule cells in the dorsal blade and practically in none in the ventral blade (Temple et al. 2003; Chawla et al. 2005). In addition, CA 3 and CA1 activity levels were not correlated within a session, arguing against unitary hippocampal activation across subregions. On the other hand, the balance of CA3/CA1 activity was highly correlated across sessions within an animal, indicating a possible source of inter-individual variance in some aspect of hippocampal function, such as spatial learning ability (Fig. 1C; Vazdarjanova and Guzowski 2004).

These experimental findings demonstrate that network dynamics in CA3 alternate between pattern separation and pattern completion in a nonlinear fashion. These findings support the idea that hippocampal subfields along the trisynaptic circuit contribute distinct, yet complementary, functions via their different network properties. This idea is consistent with studies suggesting that the hippocampus performs multiple functions (Riedel et al. 1999; Micheau et al. 2004; Kubik and Fenton 2005).

\section{Conclusions and future directions}

IEGs have been used to examine (1) the role of the hippocampus in memory; (2) specific roles of hippocampal subregions in memory acquisition, consolidation, and retrieval; (3) the theory of systems consolidation-hippocampal disengagement in memories over time; (4) functional dissociation between memory and anxiety/behavioral inhibition along the septotemporal axis of the hippocampus; and (5) different neural network properties of hippocampal subregions. IEG studies provided support for hippocampal involvement in spatial and contextual memory. While it is possible that hippocampal subfields are differentially in- volved in different phases of memory, specific task demands such as the amount of training (rapid encoding), necessity to differentiate between different but similar stimuli or responses (pattern separation), incomplete stimuli (pattern completion), or temporal discontinuities (short-term memory) are more likely to impose critical requirements for specific subregional functions. However, the activity observed in the hippocampus, including the CA3, during overtly hippocampus-independent behaviors supports the view that the hippocampus engages in continuous encoding of behavioral experience (Morris and Frey 1997). At this time, IEG studies of systems consolidation are equivocal. Converging evidence of a functional gradient along the septotemporal axis of the hippocampus emerges from IEG imaging, unit recording, and lesion studies. Finally, the catFISH technique demonstrated context-specific ensemble representations in both CA3 and CA1, close resemblance of Arc expression patterns to the electrophysiological properties of place cells, and dynamic balance between pattern separation and pattern completion in CA3 ensemble representations.

The ability of IEG imaging studies to further elucidate hippocampal subregional functions will depend on clarification of our understanding of the precise relationship between neuronal activity, IEG expression, and synaptic plasticity. For example, the significance of continued IEG expression in familiar environments or overtrained behavioral tasks may be addressed by combining IEG imaging with intervention approaches such as IEG knockout or knockdown techniques (see "Limitations of IEG Imaging Approaches" section). The roles of different hippocampal subregions may be further uncovered by combining IEG imaging with selective lesions, targeted pharmacological interventions, or reversible inactivations. Advanced IEG techniques like catFISH and regionally selective IEG knockdown may be used to investigate hippocampal correlates of contextual generalization and the involvement of hippocampus and its subregions in retaining memories over time. Subregion-specific manipulation of IEG expression may be used in concert with IEG imaging or unit recording techniques to reveal the role of subregional IEG expression in the context of hippocampal function. Adding temporal control to those manipulations (Mayford et al. 1996; Mansuy et al. 1998) may help to dissect the contributions of IEG expression in individual subregions to different stages of memory formation.

In closing, the IEG studies provide robust evidence for a role of the hippocampus in declarative learning and memory, possibly via continuous encoding of ongoing experience. The IEG studies are consistent with the idea that the hippocampus is functionally differentiated along the septotemporal axis. They also demonstrated different neural network properties of CA1 and CA3 subregions and showed evidence of competition between pattern separation and pattern completion in CA3. Taken together with findings from lesion, genetic, and recording experiments, IEG studies provide support for the role of CA3 in rapid encoding and retrieval of complex memory representations, such as those involving spatial and contextual information.

\section{Acknowledgments}

This research was supported by NIH grant MH060123 (J.F.G.).

\section{References}

Aggleton, J.P. and Brown, M.W. 1999. Episodic memory, amnesia, and the hippocampal-anterior thalamic axis. Behav. Brain Sci. 22: $425-489$.

Aggleton, J.P. and Pearce, J.M. 2001. Neural systems underlying episodic memory: Insights from animal research. Philos. Trans. $R$ Soc. Lond. B Biol. Sci. 356: 1467-1482. 
Aggleton, J.P., Hunt, P.R., and Rawlins, J.N. 1986. The effects of hippocampal lesions upon spatial and non-spatial tests of working memory. Behav. Brain Res. 19: 133-146.

Albasser, M.M., Poirier, G.L., Warburton, E.C., and Aggleton, J.P. 2007. Hippocampal lesions halve immediate-early gene protein counts in retrosplenial cortex: Distal dysfunction in a spatial memory system. Eur. J. Neurosci. 26: 1254-1266.

Amaral, D.G. and Witter, M.P. 1989. The three-dimensional organization of the hippocampal formation: A review of anatomical data. Neuroscience 31: 571-591.

Amaral, D.G. and Witter, M.P. 1995. Hippocampal formation. In The rat nervous system, 2d ed. (ed. G. Paxinos), pp. 443-493. Academic Press, San Diego.

Amin, E., Pearce, J.M., Brown, M.W., and Aggleton, J.P. 2006. Novel temporal configurations of stimuli produce discrete changes in immediate-early gene expression in the rat hippocampus. Eur. J. Neurosci. 24: 2611-2621.

Anagnostaras, S.G., Maren, S., and Fanselow, M.S. 1999. Temporally graded retrograde amnesia of contextual fear after hippocampal damage in rats: Within-subjects examination. J. Neurosci. 19: $1106-1114$.

Bannerman, D.M., Grubb, M., Deacon, R.M.J., Yee, B.K., Feldon, J., and Rawlins, J.N.P. 2003. Ventral hippocampal lesions affect anxiety but not spatial learning. Behav. Brain Res. 139: 197-213.

Bannerman, D.M., Rawlins, J.N., McHugh, S.B., Deacon, R.M., Yee, B.K., Bast, T., Zhang, W.N., Pothuizen, H.H., and Feldon, J. 2004. Regional dissociations within the hippocampus: Memory and anxiety. Neurosci. Biobehav. Rev. 28: 273-283.

Biedenkapp, J.C. and Rudy, J.W. 2007. Context preexposure prevents forgetting of a contextual fear memory: Implication for regional changes in brain activation patterns associated with recent and remote memory tests. Learn. Mem. 14: 200-203.

Bliss, T.V.P. and Lomo, T. 1973. Long-lasting potentiation of synaptic transmission in the dentate area of the anaesthetized rabbit following stimulation of the perforant path. J. Physiol. 232: 331-356.

Bostock, E., Muller, R.U., and Kubie, J.L. 1991. Experience-dependent modifications of hippocampal place cell firing. Hippocampus 1: 193-206.

Bottai, D., Guzowski, J.F., Schwarz, M.K., Kang, S.H., Xiao, B., Lanahan A., Worley, P.F., and Seeburg, P.H. 2002. Synaptic activity-induced conversion of intronic to exonic sequence in Homer 1 immediate-early gene expression. J. Neurosci. 22: 167-175.

Brakeman, P.R., Lanahan, A.A., O'Brien, R., Roche, K., Barnes, C.A., Huganir, R.L., and Worley, P.F. 1997. Homer: A protein that selectively binds metabotropic glutamate receptors. Nature 386: $284-288$.

Broadbent, N.J., Squire, L.R., and Clark, R.E. 2006. Reversible hippocampal lesions disrupt water maze performance during both recent and remote memory tests. Learn. Mem. 13: 187-191.

Calfa, G., Bussolino, D., and Molina, V.A. 2007. Involvement of the lateral septum and the ventral hippocampus in the emotional sequelae induced by social defeat: Role of glucocorticoid receptors. Behav. Brain Res. 181: 23-34.

Chan, K.-H., Morell, J.R., Jarrard, L.E., and Davidson, T.L. 2001. Reconsideration of the role of the hippocampus in learned inhibition. Behav. Brain Res. 119: 111-130.

Chawla, M.K., Guzowski, J.F., Ramirez-Amaya, V., Lipa, P., Hoffman, K.L., Marriott, L.K., Worley, P.F., McNaughton, B.L., and Barnes, C.A. 2005. Sparse, environmentally selective expression of Arc RNA in the upper blade of the rodent fascia dentata by brief spatial experience. Hippocampus 15: 579-586.

Chowdhury, S., Shepherd, J.D., Okuno, H., Lyford, G., Petralia, R.S., Plath, N., Kuhl, D., Huganir, R.L., and Worley, P.F. 2006. Arc/Arg3.1 interacts with the endocytic machinery to regulate AMPA receptor trafficking. Neuron 52: 445-459.

Clark, R.E., Broadbent, N.J., and Squire, L.R. 2005. Hippocampus and remote spatial memory in rats. Hippocampus 15: 260-272.

Clayton, D.F. 2000. The genomic action potential. Neurobiol. Learn. Mem. 74: $185-216$.

Colombo, P.J., Brightwell, J.J., and Countryman, R.A. 2003. Cognitive strategy-specific increases in phosphorylated cAMP response element-binding protein and c-Fos in the hippocampus and dorsal striatum. J. Neurosci. 23: 3547-3554.

Countryman, R.A., Kaban, N.L., and Colombo, P.J. 2005. Hippocampal $c$-fos is necessary for long-term memory of a socially transmitted food preference. Neurobiol. Learn. Mem. 84: 175-183.

Cravens, C.J., Vargas-Pinto, N., Christian, K.M., and Nakazawa, K. 2006. CA3 NMDA receptors are crucial for rapid and automatic representation of context memory. Eur. J. Neurosci. 24: 1771-1780.

Davidson, T.L. and Jarrard, L.E. 2004. The hippocampus and inhibitory learning: A 'Gray' area? Neurosci. Biobehav. Rev. 28: 261-271.

Davis, S., Bozon, B., and Laroche, S. 2003. How necessary is the activation of the immediate early gene zif 268 in synaptic plasticity and learning? Behav. Brain Res. 142: 17-30.

Deacon, R.M.J., Bannerman, D.M., and Rawlins, J.N.P. 2002. Anxiolytic effects of cytotoxic hippocampal lesions in rats. Behav. Neurosci. 116: $494-497$.

Donai, H., Sugiura, H., Ara, D., Yoshimura, Y., Yamagata, K., and Yamauchi, T. 2003. Interaction of Arc with CaM kinase II and stimulation of neurite extension by Arc in neuroblastoma cells expressing CaM kinase II. Neurosci. Res. 47: 399-408.

Eldridge, L.L., Engel, S.A., Zeineh, M.M., Bookheimer, S.Y., and Knowlton, B.J. 2005. A dissociation of encoding and retrieval processes in the human hippocampus. J. Neurosci. 25: 3280-3286.

Fleischmann, A., Hvalby, O., Jensen, V., Strekalova, T., Zacher, C., Layer, L.E., Kvello, A., Reschke, M., Spanagel, R., Sprengel, R., et al. 2003. Impaired long-term memory and NR2A-type NMDA receptor-dependent synaptic plasticity in mice lacking c-Fos in the CNS. J. Neurosci. 23: 9116-9122.

Fletcher, B.R., Calhoun, M.E., Rapp, P.R., and Shapiro, M.L. 2006. Fornix lesions decouple the induction of hippocampal arc transcription from behavior but not plasticity. J. Neurosci. 26: 1507-1515.

Fletcher, B.R., Baxter, M.G., Guzowski, J.F., Shapiro, M.L., and Rapp, P.R. 2007. Selective cholinergic depletion of the hippocampus spares both behaviorally induced arc transcription and spatial learning and memory. Hippocampus 17: 227-234.

Frankland, P.W. and Bontempi, B. 2005. The organization of recent and remote memories. Nat. Rev. Neurosci. 6: 119-130.

Frankland, P.W., Bontempi, B., Talton, L.E., Kaczmarek, L., and Silva, A.J. 2004. The involvement of the anterior cingulate cortex in remote contextual fear memory. Science 304: 881-883.

Fujimoto, T., Tanaka, H., Kumamaru, E., Okamura, K., and Miki, N. 2004. Arc interacts with microtubules/microtubule-associated protein 2 and attenuates microtubule-associated protein 2 immunoreactivity in the dendrites. J. Neurosci. Res. 76: 51-63.

Gall, C.M., Hess, U.S., and Lynch, G. 1998. Mapping brain networks engaged by, and changed by, learning. Neurobiol. Learn. Mem. 70: $14-36$.

Gilbert, P.E. and Kesner, R.P. 2006. The role of the dorsal CA3 hippocampal subregion in spatial working memory and pattern separation. Behav. Brain Res. 169: 142-149.

Gilbert, P.E., Kesner, R.P., and Lee, I. 2001. Dissociating hippocampal subregions: A double dissociation between the dentate gyrus and CA1. Hippocampus 11: 626-636.

Gold, A.E. and Kesner, R.P. 2005. The role of the CA3 subregion of the dorsal hippocampus in spatial pattern completion in the rat. Hippocampus 15: 808-814.

Gray, J.A. and McNaughton, N. 2000. The neuropsychology of anxiety: An enquiry into the functions of the septo-hippocampal system. Oxford University Press, Oxford.

Gusev, P.A., Cui, C., Alkon, D.L., and Gubin, A.N. 2005. Topography of Arc/Arg3.1 RNA expression in the dorsal and ventral hippocampus induced by recent and remote spatial memory recall: dissociation of CA3 and CA1 activation. J. Neurosci. 25: 9384-9397.

Guzowski, J.F. 2002. Insights into immediate-early gene function in hippocampal memory consolidation using antisense oligonucleotide and fluorescent imaging approaches. Hippocampus 12: 86-104.

Guzowski, J.F. and McGaugh, J.L. 1997. Interaction of neuromodulatory systems regulating memory storage. In Alzheimer's disease: Molecular aspects and pharmacological treatments (eds. M. Decker and J.D. Brioni), pp. 37-61. Wiley-Liss, New York.

Guzowski, J.F., McNaughton, B.L., Barnes, C.A., and Worley, P.F. 1999. Environment-specific expression of the immediate-early gene Arc in hippocampal neuronal ensembles. Nat. Neurosci. 2: 1120-1124.

Guzowski, J.F., Lyford, G.L., Stevenson, G.D., Houston, F.P., McGaugh, J.L., Worley, P.F., and Barnes, C.A. 2000. Inhibition of activity-dependent Arc protein expression in the rat hippocampus impairs the maintenance of long-term potentiation and consolidation of long-term memory. J. Neurosci. 20: 3993-4001.

Guzowski, J.F., Setlow, B., Wagner, E.K., and McGaugh, J.L. 2001. Experience-dependent gene expression in the rat hippocampus following spatial learning: A comparison of the immediate-early genes Arc, c-fos, and zif268. J. Neurosci. 21: 5089-5098.

Guzowski, J.F., Knierim, J.J., and Moser, E.I. 2004. Ensemble dynamics of hippocampal regions CA1 and CA3. Neuron 44: 581-584.

Guzowski, J.F., Miyashita, T., Chawla, M.K., Sanderson, J., Maes, L.I., Houston, F.P., Lipa, P., McNaughton, B.L., Worley, P.F., and Barnes, C.A. 2006. Recent behavioral history modifies coupling between cell activity and Arc gene transcription in hippocampal CA1 neurons. Proc. Natl. Acad. Sci. 103: 1077-1082.

Hall, J., Thomas, K.L., and Everitt, B.J. 2001. Cellular imaging of zif268 expression in the hippocampus and amygdala during contextual and cued fear memory retrieval: Selective activation of hippocampal CA1 neurons during the recall of contextual memories. J. Neurosci. 
21: $2186-2193$.

Hebb, D.O. 1949. The organization of behaviour. Wiley, New York.

Hess, U.S., Lynch, G., and Gall, C.M. 1995a. Changes in c-fos mRNA expression in rat brain during odor discrimination learning: Differential involvement of hippocampal subfields CA1 and CA3. J. Neurosci. 15: 4786-4795.

Hess, U.S., Lynch, G., and Gall, C.M. 1995b. Regional patterns of c-fos mRNA expression in rat hippocampus following exploration of a novel environment versus performance of a well-learned discrimination. I. Neurosci. 15: 7796-7809.

Huff, N.C., Frank, M., Wright-Hardesty, K., Sprunger, D., Matus-Amat, P., Higgins, E., and Rudy, J.W. 2006. Amygdala regulation of immediate-early gene expression in the hippocampus induced by contextual fear conditioning. J. Neurosci. 26: 1616-1623.

Husi, H., Ward, M.A., Choudhary, J.S., Blackstock, W.P., and Grant, S.G. 2000. Proteomic analysis of NMDA receptor-adhesion protein signaling complexes. Nat. Neurosci. 3: 661-669.

Jenkins, T.A., Dias, R., Amin, E., and Aggleton, J.P. 2002a. Changes in Fos expression in the rat brain after unilateral lesions of the anterior thalamus. Eur. J. Neurosci. 16: 1425-1432.

Jenkins, T.A., Dias, R., Amin, E., Brown, M.W., and Aggleton, J.P. 2002b. Fos imaging reveals that lesions of the anterior thalamic nuclei produce widespread limbic hypoactivity in rats. J. Neurosci. 22: $5230-5238$.

Jenkins, T.A., Amin, E., Pearce, J.M., Brown, M.W., and Aggleton, J.P. 2004. Novel spatial arrangements of familiar visual stimuli promote activity in the rats' hippocampal formation but not the parahippocampal cortices: A c-Fos expression study. Neuroscience 124: $43-52$.

Jenkins, T.A., Amin, E., Brown, M.W., and Aggleton, J.P. 2006. Changes in immediate early gene expression in the rat brain after unilateral lesions of the hippocampus. Neuroscience 137: 747-759.

Jerman, T., Kesner, R.P., and Hunsaker, M.R. 2006. Disconnection analysis of CA3 and DG in mediating encoding but not retrieval in a spatial maze learning task. Learn. Mem. 13: 458-464.

Jonasson, Z., Ballantyne, J.K., and Baxter, M.G. 2004. Preserved anterograde and retrograde memory of rapidly acquired olfactory discriminations after neurotoxic hippocampal lesions. Hippocampus 14: $28-39$.

Jones, M.W., Errington, M.L., French, P.J., Fine, A., Bliss, T.V., Garel, S., Charnay, P., Bozon, B., Laroche, S., and Davis, S. 2001. A requirement for the immediate early gene Zif268 in the expression of late LTP and long-term memories. Nat. Neurosci. 4: 289-296.

Kaut, K.P. and Bunsey, M.D. 2001. The effects of lesions to the rat hippocampus or rhinal cortex on olfactory and spatial memory: Retrograde and anterograde findings. Cogn. Affect. Behav. Neurosci. 1: $270-286$.

Kelly, M.P. and Deadwyler, S.A. 2002. Acquisition of a novel behavior induces higher levels of Arc mRNA than does overtrained performance. Neuroscience 110: 617-626.

Kelly, M.P. and Deadwyler, S.A. 2003. Experience-dependent regulation of the immediate-early gene Arc differs across brain regions. $J$. Neurosci. 23: 6443-6451.

Kim, J.J. and Fanselow, M.S. 1992. Modality-specific retrograde amnesia of fear. Science 256: 675-677.

Kjelstrup, K.G., Tuvnes, F.A., Steffenach, H.A., Murison, R., Moser, E.I., and Moser, M.B. 2002. Reduced fear expression after lesions of the ventral hippocampus. Proc. Natl. Acad. Sci. 99: 10825-10830.

Kubik, S. and Fenton, A.A. 2005. Behavioral evidence that segregation and representation are dissociable hippocampal functions. $J$. Neurosci. 25: 9205-9212.

Lanahan, A. and Worley, P. 1998. Immediate-early genes and synaptic function. Neurobiol. Learn. Mem. 70: 37-43.

Lee, I. and Kesner, R.P. 2002. Differential contribution of NMDA receptors in hippocampal subregions to spatial working memory. Nat. Neurosci. 5: 162-168.

Lee, I. and Kesner, R.P. 2004a. Encoding versus retrieval of spatial memory: Double dissociation between the dentate gyrus and the perforant path inputs into CA3 in the dorsal hippocampus. Hippocampus 14: 66-76.

Lee, I. and Kesner, R.P. 2004b. Differential contributions of dorsal hippocampal subregions to memory acquisition and retrieval in contextual fear-conditioning. Hippocampus 14: 301-310.

Lee, M.G., Chrobak, J.J., Sik, A., Wiley, R.G., and Buzsaki, G. 1994. Hippocampal theta activity following selective lesion of the septal cholinergic system. Neuroscience 62: 1033-1047.

Lee, I., Yoganarasimha, D., Rao, G., and Knierim, J.J. 2004. Comparison of population coherence of place cells in hippocampal subfields CA1 and CA3. Nature 430: 456-459.

Lehman, H., Lacanilao, S., and Sutherland, R.S. 2007. Complete or partial hippocampal damage produces equivalent retrograde amnesia for recent and remote contextual fear memories. Eur. J. Neurosci.
26: $1278-1286$.

Leutgeb, S. and Mizumori, S.J. 1999. Excitotoxic septal lesions result in spatial memory deficits and altered flexibility of hippocampal single unit representations. J. Neurosci. 19: 6661-6672.

Leutgeb, S., Leutgeb, J.K., Treves, A., Moser, M.B., and Moser, E.I. 2004. Distinct ensemble codes in hippocampal areas CA3 and CA1. Science 305: $1295-1298$.

Leutgeb, S., Leutgeb, J.K., Barnes, C.A., Moser, E.I., McNaughton, B.L., and Moser, M.-B. 2005. Independent codes for spatial and episodic memory in the hippocampus. Science 309: 619-623.

Link, W., Konietzko, U., Kauselmann, G., Krug, M., Schwanke, B., Frey, U., and Kuhl, D. 1995. Somatodendritic expression of an immediate early gene is regulated by synaptic activity. Proc. Natl. Acad. Sci. 92: $5734-5738$.

Lorente de No, R. 1934. Studies on the structure of the cerebral cortex. II. Continuation of the study of the ammonic system. J. Psychol. Neurol. 46: 113-177.

Lyford, G.L., Yamagata, K., Kaufmann, W.E., Barnes, C.A., Sanders, L.K., Copeland, N.G., Gilbert, D.J., Jenkins, N.A., Lanahan, A.A., and Worley, P.F. 1995. Arc/Arg3.1, a growth factor and activity-regulated gene, encodes a novel cytoskeleton-associated protein that is enriched in neuronal dendrites. Neuron 14: 433-445.

Mansuy, I.M., Winder, D.G., Moallem, T.M., Osman, M., Mayford, M., Hawkins, R.D., and Kandel, E.R. 1998. Inducible and reversible gene expression with the rtTA system for the study of memory. Neuron 21: $257-265$.

Marr, D. 1971. Simple memory: A theory for archicortex. Philos. Trans. R. Soc. Lond. B Biol. Sci. 262: 23-81.

Martin, S.J., de Hoz, L., and Morris, R.G. 2005. Retrograde amnesia: Neither partial nor complete hippocampal lesions in rats result in preferential sparing of remote spatial memory, even after reminding. Neuropsychologia 43: 609-624.

Maurer, A.P., Van Rhoads, S.R., Sutherland, G.R., Lipa, P., and McNaughton, B.L. 2005. Self-motion and the origin of differential spatial scaling along the septo-temporal axis of the hippocampus. Hippocampus 15: 841-852.

Maviel, T., Durkin, T.P., Menzaghi, F., and Bontempi, B. 2004. Sites of neocortical reorganization critical for remote spatial memory. Science 305: 96-99.

Mayford, M., Bach, M., Huang, Y.-Y., Wang, L., Hawkins, R.D., and Kandel, E.R. 1996. Control of memory formation through regulated expression of a CaMKII transgene. Science 274: 1678-1683.

McClelland, J.L. and Goddard, N.H. 1996. Considerations arising from a complementary learning systems perspective on hippocampus and neocortex. Hippocampus 6: 654-665.

McClelland, J.L., McNaughton, B.L., and O’Reilly, R.C. 1995. Why there are complementary learning systems in the hippocampus and neocortex: Insight from the successes and failures of connectionist models of learning and memory. Psychol. Rev. 102: 419-457.

McDonald, R.J., Jones, J., Richards, B., and Hong, N.S. 2006. A double dissociation of dorsal and ventral hippocampal function on a learning and memory task mediated by the dorso-lateral striatum. Eur. J. Neurosci. 24: 1789-1801.

McGaugh, J.L. 2000. Memory-A century of consolidation. Science 287: 248-251.

McIntyre, C.K., Miyashita, T., Setlow, B., Marjon, K.D., Steward, O., Guzowski, J.F., and McGaugh, J.L. 2005. Memory-influencing intra-basolateral amygdala drug infusions modulate expression of Arc protein in the hippocampus. Proc. Natl. Acad. Sci. 102: $10718-10723$.

McNaughton, B.L. and Morris, R.G.M. 1987. Hippocampal enhancement and information storage within a distributed memory system. Trends Neurosci. 10: 408-415.

Micheau, J., Riedel, G., Roloff, E.L., Inglis, J., and Morris, R.G. 2004. Reversible hippocampal inactivation partially dissociates how and where to search in the water maze. Behav. Neurosci. 118: 1022-1032.

Miller, V.M. and Best, P.J. 1980. Spatial correlates of hippocampal unit activity are altered by lesions of the fornix and endorhinal cortex. Brain Res. 194: 311-323.

Mizumori, S.J.Y., McNaughton, B.L., Barnes, C.A., and Fox, K.B. 1989. Preserved spatial coding in hippocampal CA1 pyramidal cells during reversible suppression of CA3c output: Evidence for pattern completion in hippocampus. J. Neurosci. 9: 3915-3928.

Mizumori, S.J., Perez, G.M., Alvarado, M.C., Barnes, C.A., and McNaughton, B.L. 1990. Reversible inactivation of the medial septum differentially affects two forms of learning in rats. Brain Res. 528: 12-20.

Moga, D.E., Calhoun, M.E., Chowdhury, A., Worley, P., Morrison, J.H. and Shapiro, M.L. 2004. Activity-regulated cytoskeletal-associated protein is localized to recently activated excitatory synapses. Neuroscience 125: 7-11. 
Morris, R.G.M. and Frey, U. 1997. Hippocampal synaptic plasticity: Role in spatial learning or the automatic recording of attended experience? Philos. Trans. R. Soc. Lond. B Biol. Sci. 352: 1489-1503.

Morris, R.G., Garrud, P., Rawlins, J.N., and O'Keefe, J. 1982. Place navigation impaired in rats with hippocampal lesions. Nature 297: 681-683.

Moser, M.B. and Moser, E.I. 1998a. Distributed encoding and retrieval of spatial memory in the hippocampus. J. Neurosci. 18: 7535-7542.

Moser, M.B. and Moser, E.I. 1998b. Functional differentiation in the hippocampus. Hippocampus 8: 608-619.

Moser, M.B., Moser, E.I., Forrest, E., Andersen, P., and Morris, R.G. 1995. Spatial learning with a minislab in the dorsal hippocampus. Proc. Natl. Acad. Sci. 92: 9697-9701.

Muller, R.U., Kubie, J.L., and Ranck Jr., J.B. 1987. Spatial firing patterns of hippocampal complex-spike cells in a fixed environment. $J$. Neurosci. 7: 1935-1950.

Nakazawa, K., Quirk, M.C., Chitwood, R.A., Watanabe, M., Yeckel, M.F., Sun, L.D., Kato, A., Carr, C.A., Johnston, D., Wilson, M.A., et al. 2002. Requirement for hippocampal CA3 NMDA receptors in associative memory recall. Science 297: 211-218.

Nakazawa, K., Sun, L.D., Quirk, M.C., Rondi-Reig, L., Wilson, M.A., and Tonegawa, S. 2003. Hippocampal CA3 NMDA receptors are crucial for memory acquisition of one-time experience. Neuron 38: 305-315.

Nascimento Häckl, L.P. and Carobrez, A.P. 2007. Distinct ventral and dorsal hippocampus AP5 anxiolytic effects revealed in the elevated plus-maze task in rats. Neurobiol. Learn. Mem. 87: 177-185.

O'Keefe, J. and Dostrovsky, J. 1971. The hippocampus as a spatial map: Preliminary evidence from unit activity in the freely-moving rat. Brain Res. 34: 171-175.

O'Keefe, J. and Nadel, L. 1978. The hippocampus as a cognitive map. Oxford University Press, Oxford.

Olton, D.S., Becker, J.T., and Handelmann, G.E. 1979. Hippocampus, space and memory. Behav. Brain Sci. 2: 313-365.

O'Reilly, R.C. and Rudy, J.W. 2001. Conjunctive representations in learning and memory: Principles of cortical and hippocampal function. Psychol. Rev. 108: 311-345.

Packard, M.G. and McGaugh, J.L. 1996. Inactivation of hippocampus or caudate nucleus with lidocaine differentially affects expression of place and response learning. Neurobiol. Learn. Mem. 65: 65-72.

Pentkowski, N.S., Blanchard, D.C., Lever, C., Litvin, Y., and Blanchard, R.J. 2006. Effects of lesions to the dorsal and ventral hippocampus on defensive behaviors in rats. Eur. J. Neurosci. 23: 2185-2196.

Pikkarainen, M., Ronkko, S., Savander, V., Insausti, R., and Pitkanen, A 1999. Projections from the lateral, basal, and accessory basal nuclei of the amygdala to the hippocampal formation in rat. J. Comp. Neurol. 403: 229-260.

Plath, N., Ohana, O., Dammermann, B., Errington, M.L., Schmitz, D. Gross, C., Mao, X., Engelsberg, A., Mahlke, C., Welzl, H., et al. 2006. Arc/Arg3.1 is essential for the consolidation of synaptic plasticity and memories. Neuron 52: 437-444.

Pothuizen, H.H.J., Zhang, W.-N., Jongen-Relo, A.L., Feldon, J., and Yee, B.K. 2004. Dissociation of function between the dorsal and ventral hippocampus in spatial learning abilities of the rat: A within-subject, within-task comparison of reference and working spatial memory. Eur. J. Neurosci. 19: 705-712.

Quirk, G.J., Muller, R.U., and Kubie, J.L. 1990. The firing of hippocampal place cells in the dark reflects the rat's recent experience. J. Neurosci. 10: 2008-2017.

Rajji, T., Chapman, D., Eichenbaum, H., and Greene, R. 2006. The role of CA3 hippocampal NMDA receptors in paired associate learning. $J$. Neurosci. 26: 908-915.

Ramón y Cajal, S. 1893. Estructura del Asta de Ammon y fascia dentata. Ann Soc. Esp. Hist. Nat. 22.

Rapp, P.R. and Gallagher, M. 1996. Preserved neuron number in the hippocampus of aged rats with spatial learning deficits. Proc. Natl. Acad. Sci. 93: 9926-9930.

Rapp, P.R., Rosenberg, R.A., and Gallagher, M. 1987. An evaluation of spatial information processing in aged rats. Behav. Neurosci. 101: $3-12$.

Rawlins, J.N., Feldon, J., and Gray, J.A. 1979. Septo-hippocampal connections and the hippocampal theta rhythm. Exp. Brain Res. 37: 49-63.

Rial Verde, E.M., Lee-Osbourne, J., Worley, P.F., Malinow, R., and Cline, H.T. 2006. Increased expression of the immediate-early gene Arc/Arg3.1 reduces AMPA receptor-mediated synaptic transmission. Neuron 52: 461-474.

Ribeiro, S. and Nicolelis, M.A. 2004. Reverberation, storage, and postsynaptic propagation of memories during sleep. Learn. Mem. 11: $686-696$.

Riedel, G., Micheau, J., Lam, A.G., Roloff, E., Martin, S.J., Bridge, H.,
Hoz, L., Poeschel, B., McCulloch, J., and Morris, R.G. 1999. Reversible neural inactivation reveals hippocampal participation in several memory processes. Nat. Neurosci. 2: 898-905.

Rolls, E.T. and Kesner, R.P. 2006. A computational theory of hippocampal function, and empirical tests of the theory. Prog. Neurobiol. 79: 1-48.

Rolls, E.T. and Treves, A. 1998. Neural networks and brain function. Oxford University Press, Oxford.

Rudy, J.W., Biedenkapp, J.C., and O'Reilly, R.C. 2005. Prefrontal cortex and the organization of recent and remote memories: An alternative view. Learn. Mem. 12: 445-446.

Sala, C., Futai, K., Yamamoto, K., Worley, P.F., Hayashi, Y., and Sheng, M. 2003. Inhibition of dendritic spine morphogenesis and synaptic transmission by activity-inducible protein Homer 1a. J. Neurosci. 23: 6327-6337.

Sargolini, F., Fyhn, M., Hafting, T., McNaughton, B.L., Witter, M.P., Moser, M.-B., and Moser, E.I. 2006. Conjunctive representation of position, direction, and velocity inentorhinal cortex. Science 312: $758-762$.

Scoville, W.B. and Milner, B. 1957. Loss of recent memory after bilateral hippocampal lesions. J. Neurol. Neurosurg. Psychiatr. 20: 11-21.

Shapiro, M.L., Simon, D.K., Olton, D.S., Gage III, F.H., Nilsson, O., and Bjorklund, A. 1989. Intrahippocampal grafts of fetal basal forebrain tissue alter place fields in the hippocampus of rats with fimbria-fornix lesions. Neuroscience 32: 1-18.

Shepherd, J.D., Rumbaugh, G., Wu, J., Chowdhury, S., Plath, N., Kuhl, D., Huganir, R.L., and Worley, P.F. 2006. Arc/Arg3.1 mediates homeostatic synaptic scaling of AMPA receptors. Neuron 52: $475-484$.

Smith, C.A., Countryman, R.A., Sahuque, L.L., and Colombo, P.J. 2007 Time-courses of Fos expression in rat hippocampus and neocortex following acquisition and recall of a socially transmitted food preference. Neurobiol. Learn. Mem. 88: 65-74.

Squire, L.R. and Alvarez, P. 1995. Retrograde amnesia and memory consolidation: A neurobiological perspective. Curr. Opin. Neurobiol. 5: $169-177$.

Squire, L.R., Stark, C.E.L., and Clark, R.E. 2004. The medial temporal lobe. Annu. Rev. Neurosci. 27: 279-306.

Stark, C.E.L. and Squire, L.R. 2001. When zero is not zero: The problem of ambiguous baseline conditions in fMRI. Proc. Natl. Acad. Sci. 98: $12760-12766$.

Steward, O. and Worley, P.F. 2001. Selective targeting of newly synthesized Arc mRNA to active synapses requires NMDA receptor activation. Neuron 30: 227-240.

Steward, O., Wallace, C.S., Lyford, G.L., and Worley, P.F. 1998. Synaptic activation causes the mRNA for the IEG Arc/Arg3.1 to localize selectively near activated postsynaptic sites on dendrites. Neuron 21: 741-751.

Sutherland, R.J., Weisend, M.P., Mumby, D., Astur, R.S., Hanlon, F.M., Koerner, A., Thomas, M.J., Wu, Y., Moses, S.N., Cole, C., et al. 2001. Retrograde amnesia after hippocampal damage: Recent vs. remote memories in two tasks. Hippocampus 11: 27-42.

Takei, N., Inamura, N., Kawamura, M., Namba, H., Hara, K., Yonezawa, K., and Nawa, H. 2004. Brain-derived neurotrophic factor induces mammalian target of rapamycin-dependent local activation of translation machinery and protein synthesis in neuronal dendrites. J. Neurosci. 24: 9760-9769.

Taubenfeld, S.M., Wiig, K.A., Bear, M.F., and Alberini, C.M. 1999. A molecular correlate of memory and amnesia in the hippocampus. Nat. Neurosci. 2: 309-310.

Taubenfeld, S.M., Milekic, M.H., Monti, B., and Alberini, C.M. 2001. The consolidation of new but not reactivated memory requires hippocampal C/EBP. Nat. Neurosci. 4: 813-818.

Teixeira, C.M., Pomedli, S.R., Maei, H.R., Kee, N., and Frankland, P.W. 2006. Involvement of the anterior cingulate cortex in the expression of remote spatial memory. J. Neurosci. 26: 7555-7564.

Temple, M.D., Worley, P.F., and Steward, O. 2003. Visualizing changes in circuit activity resulting from denervation and reinnervation using immediate early gene expression. J. Neurosci. 23: 2779-2788.

Tischmeyer, W. and Grimm, R. 1999. Activation of immediate early genes and memory formation. Cell. Mol. Life Sci. 55: 564-574.

Vann, S.D., Brown, M.W., Erichsen, J.T., and Aggleton, J.P. 2000a. Fos imaging reveals differential patterns of hippocampal and parahippocampal subfield activity in response to different spatial memory tasks. J. Neurosci. 20: 2711-2718.

Vann, S.D., Brown, M.W., Erichsen, J.T., and Aggleton, J.P. 2000b. Using Fos imaging in the rat to reveal the anatomical extent of the disruptive effects of fornix lesions. J. Neurosci. 20: 8144-8152.

Vargha-Khadem, F., Gadian, D.G., Watkins, K.E., Connelly, A., Van Paesschen, W., and Mishkin, M. 1997. Differential effects of early hippocampal pathology on episodic and semantic memory. Science 277: $376-380$. 
Vazdarjanova, A. and Guzowski, J.F. 2004. Differences in hippocampal neuronal population responses to modifications of an environmental context: Evidence for distinct, yet complementary, functions of CA3 and CA1 ensembles. J. Neurosci. 24: 6489-6496.

Vazdarjanova, A., McNaughton, B.L., Barnes, C.A., Worley, P.F., and Guzowski, J.F. 2002. Experience-dependent coincident expression of the effector immediate-early genes arc and Homer 1a in hippocampal and neocortical neuronal networks. J. Neurosci. 22: $10067-10071$

Vazdarjanova, A., Ramirez-Amaya, V., Insel, N., Plummer, T.K., Rosi, S. Chowdhury, S., Mikhael, D., Worley, P.F., Guzowski, J.F., and Barnes, C.A. 2006. Spatial exploration induces $A R C$, a plasticity-related immediate-early gene, only in calcium/calmodulin-dependent protein kinase II-positive principal excitatory and inhibitory neurons of the rat forebrain. J. Comp. Neurol. 498: 317-329.

Wan, H., Aggleton, J.P., and Brown, M.W. 1999. Different contributions of the hippocampus and perirhinal cortex to recognition memory. $J$. Neurosci. 19: 1142-1148.

Weitemier, A.Z. and Ryabinin, A.E. 2004. Subregion-specific differences in hippocampal activity between Delay and Trace fear conditioning: An immunohistochemical analysis. Brain Res. 995: 55-65.

Wiltgen, B.J. and Silva, A.J. 2007. Memory for context becomes less specific with time. Learn. Mem. 14: 313-317.

Winocur, G., Moscovitch, M., and Sekeres, M. 2007. Memory consolidation or transformation: Context manipulation and hippocampal representations of memory. Nat. Neurosci. 10: 555-557.

Yin, Y., Edelman, G.M., and Vanderklish, P.W. 2002. The brain-derived neurotrophic factor enhances synthesis of Arc in synaptoneurosomes. Proc. Natl. Acad. Sci. 99: 2368-2373.

Received July 10, 2007; accepted in revised form September 28, 2007. 


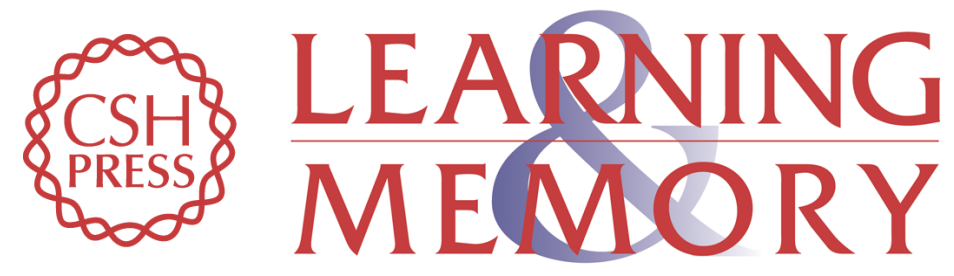

\section{Using immediate-early genes to map hippocampal subregional functions}

Stepan Kubik, Teiko Miyashita and John F. Guzowski

Learn. Mem. 2007, 14:

Access the most recent version at doi:10.1101//m.698107

References This article cites 150 articles, 55 of which can be accessed free at: http://learnmem.cshlp.org/content/14/11/758.full.html\#ref-list-1

License

Email Alerting Receive free email alerts when new articles cite this article - sign up in the box at the Service top right corner of the article or click here. 